\title{
Allometric relationships for estimating stem volume of rubber tree (Hevea brasiliensis muell-arg.) in Bangladesh
}

\begin{abstract}
The estimation of stem volume is needed for both sustainable planning of forest resources and for studies on the energy and nutrients flows in ecosystems. Tree volume equation provide to the tree biomass and carbon estimation in non-destructive way. The aim of this study is to developed allometric relationships for estimating stem volumes of rubber tree (Hevea brasiliensis Muell-Arg.) were investigated in monoculture plantations of Bangladesh. The various allometric relationships between stem volume and different tree dimensions were tested and the values of coefficient of determination $\left(R^{2}\right)$ were used to compare strength of these relationships. Although the allometric equations were highly significant $(P<0.001)$, there were considerable variations among them which was also indicated by $R^{2}$ value. The results suggested that tree volume is more correlated with simple $G$ (stem girth at $1.3 \mathrm{~m}$ height from ground). The allometric relationships of stem volume to various dimensions such as $G^{2}$ and $L n G$ did not improve the allometric strength in comparison to simple $G$ which was also reported for some other tree species. The multiplication of tree height, $H$ and girth, $G$ in the allometric equation gives a little improvement to consider the degree of fitness. However, in this plantation, girth at breast height, $G B H$ only showed a very strong accuracy of estimation $\left(R^{2}=0.953\right)$ especially when used variable $G$. Therefore, for stem volume estimation, it is recommended to use independent variable $G^{2}$ in the allometric equation. The paper describes the tree volume allometry in details which has significant importance in the field of silviculture and forest management.
\end{abstract}

Keywords: allometry, monoculture plantation, regression, rubber tree, stem volume
Volume I Issue I - 2017

\author{
Zahirul Islam SM,' Mohammad Rahmat \\ Ullah ${ }^{2}$ \\ 'Bangladesh Forest Research Institute, Bangladesh \\ ${ }^{2}$ College of Forestry, Beijing Forestry University, China
}

Correspondence: Zahirul Islam SM, Bangladesh Forest Research Institute, Box 273, Chittagong/4000, Bangladesh, Email zahir.fid.bfri@gmail.com

Received: June 12, 2017 | Published: July 27, 2017

\section{Introduction}

Rubber is a native tree species of Amazon natural forest of South America. In 1910, a few seedlings of this species were first introduced in tea gardens of Baromashia (Chittagong district) and Amu (Sylhet district) in Bangladesh from the Calcutta Botanical Garden. ${ }^{1}$ Experimental plantations of the species were done in 1954 by the Forest Department at Madhupur of Tangail, Hazarikheel of Chittagong and Tetulia of Panchaghar districts. In 1960, commercial plantation was first done by the Forest Department in land areas of 4 ha at Raojan of Chittagong and 12 ha at Ramu of Cox's Bazar districts. In 1962, commercial plantation of rubber was handed over to the Bangladesh Forest Industries Development Corporation (BFIDC), which was then started further plantations in Chittagong, Sylhet, Tangail and Sherpur districts of Bangladesh. ${ }^{2}$ During the period between 1962 and 1997, Chittagong Hill Tracts Development Board (CHTDB), several multi-national companies and private entrepreneurs raised rubber plantations. Until 2005, all these organizations raised about 27,386 ha of rubber plantation in different parts of the country. ${ }^{3}$

Rubber plantation initially was done mainly for latex production, and still now all efforts were given to increase the yield of latex. In most cases, government and private owners both are in losses to sell latex only. ${ }^{4}$ Thus, use of rubber wood in furniture making and other end products in addition to yield of latex would be profitable. ${ }^{5}$ In Malaysia, rubber wood is extensively used in wood processing industries. The utilization of rubber wood as furniture, pulp, plywood, decorative veneer and novelty items was initiated by the Forest Research Institute of Malaysia in $1953 .{ }^{6}$ Moreover, export of furniture made from rubber wood was doubled in 2008 compared to $1998 .{ }^{4}$ Thailand and Indonesia have also been actively processing and utilizing rubber wood in furniture making which was exported worldwide. ${ }^{7}$

In some BFIDC rubber plantations, age of tree was reached more than 40 years, and from that age the latex production become stagnant. After clear-felling, it is needed to replant the vacant areas. To estimate the production of total stem volume before clear felling, it is necessary to establish the volume table through the allometric equations. The volume tables for tree species are necessary for economic evaluation, future management, utilization, research purposes and to estimate the quantity of wood during the harvesting. ${ }^{8}$ But, in case of rubber trees, allometric relationships for stem volume are not available in Bangladesh. Foresters traditionally derive timber volumes by applying the allometric technique. Allometric relationship for estimating stand volume as well as forest biomass is very important for managing any natural or artificial forest resources..$^{9}$ In the estimation of stand volume, the uncertainty appears due to measurement of basal area, and the use of a mean form factor which is related to mean tapering. ${ }^{9}$ Thus, allometric relationships offer better estimation of forest standing volume, which is also an important parameter in further research such as estimation of biomass and carbon emissions, and to avoid the uncertainties for bole-volume estimation. ${ }^{9,10}$ Therefore, to choose a suitable functional variable in the allometric equation is very important for allometric techniques in forest science. ${ }^{10,11}$

There are various independent variables in the allometric relationships to estimate biomass. In most studies, $D / G$ (diameter/girth at breast height, $1.3 \mathrm{~m}$ from ground) was taken as the only independent 
variable in the allometric equation. ${ }^{12,13}$ However, incorporation of the variable $H$ (tree height i.e., the use of $D^{2} H / G^{2} H$ ) ensures higher accuracy of allometric estimation in some tree species. ${ }^{14,15}$ Moreover, the use of the new variable $D^{2}{ }_{01} H\left(D_{01}\right.$, diameter at one-tenth of $H$ ) instead of $D^{2} H$ has been suggested to improve the accuracy of estimation. ${ }^{11}$ Found a strong allometric relationship between the girth (at the point immediately before branching) of main branches of a tree and branch dry weight in a stand of Eucalyptus obliqua L' Herit. The use of $D_{\mathrm{B}}$ (stem diameter at a height of clear bole length) provides better results for estimating the weight of branch and leaf, and leaf area per tree, which was described in the pipe model theory. ${ }^{16}$ Various allometric equations have been developed from different tropical species. ${ }^{17}$ It is evident that main tree species of dicotyledonous differ in allometry because of distinctive bole shape. The allometric equations developed for yield estimation of different tree species is useful for large-scale inventories. In this paper, we established the allometric relationships of individual tree volume and different tree dimensions, such as $G$ (easy to measure), $H, G^{2}, G^{2} H$, and to propose a standard method for predicting the rubber tree volume on nondestructive way.

\section{Materials and methods}

\section{Study site}

The study was conducted in block plantations of rubber tree those are available at Ramu of Cox's Bazar, Hiako of Chittagong and Phirgacha of Tangail in Bangladesh. The area belongs to subtropical region where the rubber tree is one of the important plantation species.

\section{Measurement of trees}

Data were collected from study sites in January to June, 2016. In total, 583 standing rubber trees were represented into different girth classes whereas those were selected randomly for preparation of allometric relationship for stem volume and tables. Tree girth at breast height $(G B H, \mathrm{~cm})$ and total height, $\mathrm{m}$ was measured with Measuring tape and Haga-altimeter, respectively. The collected data were categorized based on tree $G B H$ and height classes (Table 1). The girth at one meter interval was measured by climbing the trees with a ladder.

Table I GBH-height class distribution of the sampled tree

\begin{tabular}{lllllll}
\hline GBH class & \multicolumn{6}{l}{ Number of tree in different height classes (M) } \\
\hline $\mathbf{( c m})$ & $9 \mathrm{~m}$ & $14 \mathbf{m}$ & $19 \mathbf{m}$ & $24 \mathrm{~m}$ & $29 \mathrm{~m}$ & Total \\
\hline 40 & 14 & 40 & & & 54 & 54 \\
60 & 2 & 70 & 31 & 6 & 1 & 110 \\
80 & 1 & 44 & 44 & 6 & & 95 \\
100 & & 18 & 36 & 21 & 1 & 76 \\
120 & & 12 & 44 & 25 & 12 & 93 \\
140 & & 6 & 43 & 23 & 15 & 87 \\
160 & & 1 & 23 & 19 & 2 & 45 \\
180 & & & 4 & 9 & & 13 \\
200 & & & 2 & 5 & & 7 \\
240 & & & & 2 & 1 & 3 \\
Total & 17 & 191 & 227 & 116 & 32 & 583 \\
\hline
\end{tabular}

\section{Data compilation and allometric relations computation}

Volumes of all sections except the top and bottom sections were calculated using the Smalian's formula. ${ }^{18}$ In determining the volume of bottom sections, the formula used for volume calculation of a cylinder was considered. Assuming the top section as cone, the volume was computed to one-third of the cylindrical volume of the portion. We considered the top end diameter measurement for each tree as the base diameter of the cone. The simple allometric equation is generally written using the power curve ${ }^{11}$ in the form showed in equation 1 :

$$
\text { Power; } y=a x^{b}
$$

where $y$ is the dependent variable and $x$ is the independent variable, and $a$ is the coefficient and $b$ is the allometric constant. The equation is linearized by taking logarithms, as follows (equation 2):

$$
\ln (y)=\ln (a)+\mathrm{b} \ln (\mathrm{x})
$$

Where $\ln (a)$ and $b$ are the intercept and slope of the regression line, respectively. The $\ln (a)$ and $b$ are obtained by the method of least squares. In this study, the allometric relationships of the volume and different dimensions such as $G, H, G^{2}$, and $G^{2} H$ were also established

\begin{tabular}{|c|c|}
\hline Linear & $y=a+b x$ \\
\hline Exponential & $v=0.00002583 \times G B H^{2.15}$ \\
\hline Logarithmic & $y=a+b \log x$ \\
\hline Quadratic & $y=a+b x+c x^{2}$ \\
\hline Cubic & $y=a+b x+c x^{2}+d x^{3}$ \\
\hline
\end{tabular}
using following equations (equation from 3 to 7 ):

The coefficient of determination $R^{2}$ was calculated using the following equation (based on the real data before logarithmic transformation, equation. 8):

$$
R^{2}=1-\frac{\sum_{i=1}^{n}\left(y_{i}-\hat{y}_{i}\right)^{2}}{\sum_{i=1}^{n}\left(y_{i}-\bar{y}_{i}\right)^{2}}
$$

Where $y_{i}$ is the observed value, $\hat{y}_{i}$ is the corresponding values calculated from the regression line, and $\bar{y}$ is the mean of the observed values. The $R^{2}$ value is a measure of the goodness-of-fit between the observed and calculated values.

\section{Results and discussion}

In this study, eight allometric equations were developed for data fitting. This is illustrated by the coefficient of determination using $G$, where the power equation $\left(R^{2}=0.953\right.$, Table 2$)$ shows better fitting than quadratic, cubic and exponential equation $\left(R^{2}=0.898\right)$. The lowest coefficient of determination attains at logarithmic equation $\left(R^{2}=0.762\right)$ than linear equation $\left(R^{2}=0.869\right)$. When $G$ values are squared, the power equation $\left(R^{2}=0.953\right.$, Table 2$)$ is also best fitted from others. In this case, the coefficient of determination of the polynomial cubic, polynomial quadratic, linear, exponential and logarithmic equations are showed $R^{2}=0.899, R^{2}=0.898, R^{2}=0.896, R^{2}=0.766$ and $R^{2}=0.762$ respectively. The polynomial cubic and polynomial quadratic equation shows close stronger relationship $\left(R^{2}=0.894 \& R^{2}=0.890\right)$ than linear equation $\left(R^{2}=0.762\right.$, Table 2$)$ and logarithmic equation $\left(R^{2}=0.730\right)$ 
when independent variable is $L n G$. In this case, the power and exponential equations both showed the best fit as the $R^{2}$ value (0.953), which was also the highest from others. By incorporation of tree height $H$ in the allometric equation gives a better fitting in polynomial cubic equation $\left(R^{2}=0.939\right)$, polynomial quadratic equation $\left(R^{2}=0.938\right)$ and the linear equation $\left(R^{2}=0.927\right)$, specially for both $G^{2} H$. The power equation $\left(R^{2}=0.969\right)^{19}$ gives the best fit from others and the lowest fit equation is logarithmic equation $\left(R^{2}=0.767\right)$. Hence, to be considered all independent variables, the power equation gives the best allometric relationship to estimate the stem volume of the species. The allometric relationships of rubber tree volume and independent variable of $G, G^{2}$, $L n G$ and $G^{2} H$ was illustrated in Figure 1a-1d. The scatter plot shows a non-linear trend when $G$, and $\operatorname{Ln} G$ was used as independent variable (Figure 1a-1c). This trend is changed to linear distribution if $G^{2}$ and $G^{2} H$ were used (Figure 1).

Table 2 Relationships s

\begin{tabular}{|c|c|c|c|c|c|c|c|c|}
\hline Variable & $\mathbf{E q}^{\mathrm{n}}$ & $\mathbf{A}$ & B & C & D & $\mathbf{R}^{2}$ & $\mathbf{F}$ & Sign \\
\hline \multirow[t]{6}{*}{ G } & LIN & -0.461 & 0.011 & - & - & 0.869 & 3870.87 & $<0.001$ \\
\hline & LOG & -3.292 & 0.866 & - & - & 0.762 & 1867.04 & $<0.001$ \\
\hline & QUA & -0.095 & 0.002 & 4.44E-05 & - & 0.898 & 2553.22 & $<0.001$ \\
\hline & CUB & -0.032 & $-1.45 \mathrm{E}-04$ & $6.62 \mathrm{E}-05$ & $-6.50 \mathrm{E}-08$ & 0.898 & 1702.77 & $<0.001$ \\
\hline & POW & $2.59 \mathrm{E}-05$ & 2.15 & - & - & 0.953 & 11862.24 & $<0.001$ \\
\hline & EXP & 0.037 & 0.024 & - & - & 0.898 & 5106.58 & $<0.001$ \\
\hline \multirow[t]{6}{*}{$\mathrm{G}^{2}$} & LIN & -0.005 & $5.4 \mathrm{IE}-05$ & - & - & 0.896 & 5031.32 & $<0.001$ \\
\hline & LOG & -3.292 & 0.433 & - & - & 0.762 & 1867.05 & $<0.001$ \\
\hline & QUA & -0.027 & 5.9IE-05 & $-1.65 \mathrm{E}-10$ & - & 0.898 & 2552.61 & $<0.001$ \\
\hline & CUB & -0.052 & 6.77E-05 & $-7.30 \mathrm{E}-10$ & $8.89 \mathrm{E}-15$ & 0.899 & 1719.47 & $<0.001$ \\
\hline & POW & $2.59 \mathrm{E}-05$ & 1.075 & - & - & 0.953 & 11863.25 & $<0.001$ \\
\hline & EXP & 0.114 & I.IIE-04 & - & - & 0.766 & 1906.9 & $<0.001$ \\
\hline \multirow[t]{6}{*}{$L_{n} G$} & LIN & -3.292 & 0.866 & - & - & 0.762 & 1867.05 & $<0.001$ \\
\hline & LOG & -4.879 & 3.656 & - & - & 0.73 & $|572.5|$ & $<0.001$ \\
\hline & QUA & 11.818 & -6.156 & 0.807 & - & 0.89 & 2347.2 & $<0.001$ \\
\hline & CUB & 3.052 & -0.624 & 0.11 & - & 0.894 & 2441.05 & $<0.001$ \\
\hline & POW & $3.75 \mathrm{E}-07$ & 9.279 & - & - & 0.953 & 11767.52 & $<0.001$ \\
\hline & EXP & $2.59 \mathrm{E}-05$ & 2.15 & - & - & 0.953 & 11863.25 & $<0.001$ \\
\hline \multirow[t]{6}{*}{$\mathrm{G} 2 \mathrm{H}$} & LIN & 0.63 & $2.60 \mathrm{E}-06$ & - & - & 0.927 & 7385.2 & $<0.001$ \\
\hline & LOG & -3.615 & 0.358 & - & - & 0.767 & 1916.22 & $<0.001$ \\
\hline & QUA & 0.018 & $3.13 \mathrm{E}-06$ & $-8.27 \mathrm{E}-13$ & - & 0.938 & 4401.24 & $<0.001$ \\
\hline & CUB & 0.005 & $3.38 \mathrm{E}-06$ & $-1.56 \mathrm{E}-12$ & $4.85 \mathrm{E}-19$ & 0.939 & 2958.67 & $<0.001$ \\
\hline & POW & I. I0E-05 & 0.893 & - & - & 0.969 & 18233.89 & $<0.001$ \\
\hline & EXP & 1.36 & $5.13 \mathrm{E}-06$ & - & - & 0.73 & 1576.89 & $<0.001$ \\
\hline
\end{tabular}

Notes $\mathrm{Eq}^{n}$ is equation, $\mathrm{H}$ is tree height in $\mathrm{m}, \mathrm{G}$ is stem girth in $\mathrm{cm}, \mathrm{LIN}$ is linear, LOG is logarithmic, QUA is quadratic, CUB is cubic, POW is power, and EXP is exponential

Although the allometric equations were highly significant $(P<0.001)$ there was considerable variation among them as indicated by the $R^{2}$ values (Table 2). The scatter plotting (Figure 1) shows a non-linear trend for $G$, and $\operatorname{Ln} G$ as independent variable, which becomes linear when plotted against $G^{2}$. This indicates that tree volume is more correlated with girth at breast height. ${ }^{20}$ Using the simple $G$ as independent variable in the allometric equation, the power equation showed the best fit $\left(R^{2}=0.953\right)$ with a close estimate by the polynomial quadratic equation, polynomial cubic equation and exponential equation as same coefficient of determination $\left(R^{2}\right.$ $=0.898)$. However, there were low differences in the goodness-offit among the logarithmic and linear equations. There were several coefficients required for quadratic and cubic equations. Considering simplicity and practical uses, the linear or power equations should be preferred to estimate stand volume whereas $G^{2}$ as an independent variable. ${ }^{11}$ Likewise, variable $G$, it showed that the strong linear data fitting for power equation $\left(R^{2}=0.953\right)$ in the allometry (Table 2$)$. This degree of linearity was exactly same for others independent variables. Overall, it may be remarked that the allometric relationships between stem volume and other independent variables did not improve the allometric strength for this species in comparison with simple $G$, as reported for some of the tree species. ${ }^{11}$ The multiplication of tree height $H$ with $G$ in the allometric equation gives high degree of linearity for the variables $G^{2} H\left(R^{2}=0.969\right)$ in the allometric 
estimation. This suggests that biologically tree diameter and height change proportionality with the change of tree size. ${ }^{11}$ Hence, $H$ is incorporated in the allometric equations, the polynomial cubic and quadratic equations showed a similar degree of fitting in comparison with linear equation for variable of $G^{2} H$ due to its simplicity. The linear equation would be preferred for indirect estimation in the field with a good level of accuracy $\left(R^{2}=0.939\right)$. Therefore, for commonly known, simple independent variable selected in allometric relationship for estimating stand tree volume in this study is power equation to this form as:

$$
\text { Stem volume, } v=0.00002583 \times G B H^{2.15}
$$

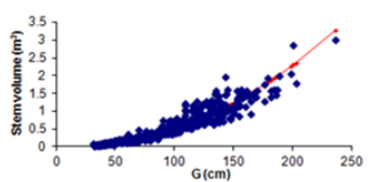

(A)

(C)

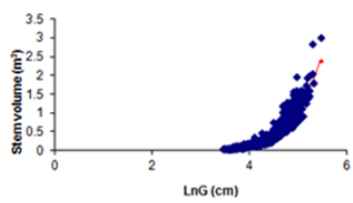

(B)

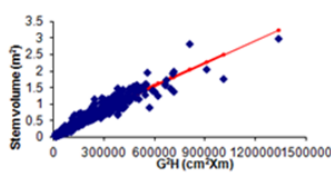

(D)

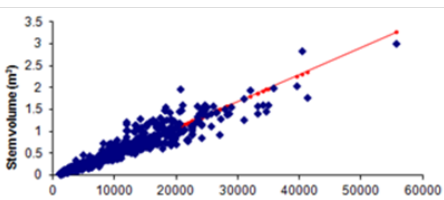

Figure I Allometric Relationships of Stem Volume Corresponding To (A) G, (B) $G^{2}$, (C) $\operatorname{Lng}\left(\right.$ D) $G^{2} H$.

To predict timber yield, in most cases, the foresters often combines trunk diameter or girth and height measurements as the independent variables in allometric relationships. However, in this study, the stem $G B H$ alone showed a very strong close accuracy of estimation especially when used as variables of $G^{2}$ and $G^{2} H$. Thus, from this study, it is concluded that the use of tree height in the allometric equation can be neglected. Therefore, to estimate the stem volume of rubber tree, it is recommended that the use of independent variables of $G^{2}$ and $G^{2} H$ in the allometric equation of linear or quadratic or cubic. The predicated allometric equation for estimating stem volume of Rubber tree also satisfies biological requirement that is sigmoid (Figure 2).

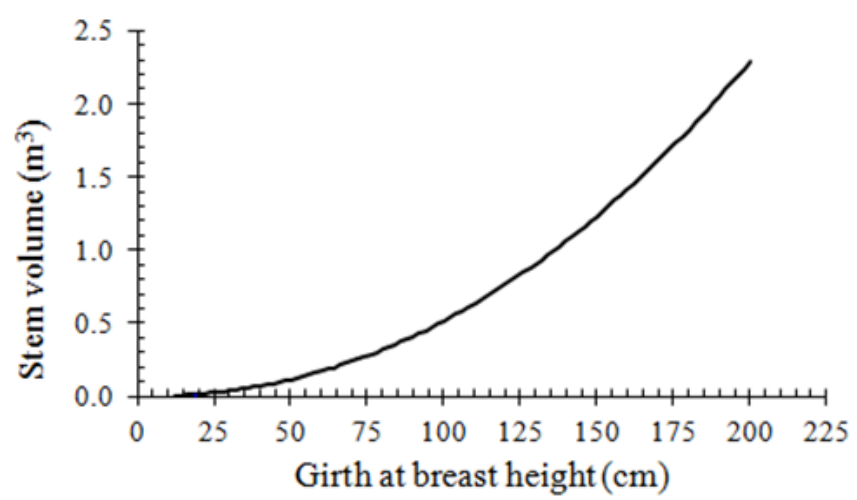

Figure 2 Predicted Allometric Relationships for Stem Volume of Rubber Tree (Hevea Brasiliensis Muell-Arg.).

\section{Conclusion}

In conclusion, it is clear that there is a variation within the independent variables of allometric equations which was used for estimating the stem volume of the species. However, the allometric relationships described in this paper for mono-specific and closed canopy conditions have limited uses for mixed or open forest stands. For estimation stem volume outside these size ranges of this investigation, it should take proper care to extrapolate the present allometric relationships. Therefore, users of these allometric equations are recommended to check some individual trees outside the present size class.

\section{Acknowledgements}

None.

\section{Conflict of interest}

Author declares that there is no conflict of interest.

\section{References}

1. Ali M. Bangladeshi Rubber Gaser Autit, Bartaman abong Bhabiswat (in Bangla) Rubber Bichitra. Yearly Journal of BFIDC. Dhaka, Bangladesh; $1985 ; 73: 1-3$

2. BFIDC. Revised Project Proposal for Second Rubber Development Project, Tangail and Sherpur Region, Planning and Development Division, Government of the Peoples' Republic of Bangladesh. 1995. p. 131.

3. Sarkar MAH. Bangladeshe rubber Chashebonger Bhabissat (In Bangali). Bangladesh: Bangladesh Forest Industries Development Corporation. Dhaka; 2006. p. 6.

4. Arokiaraj P, Jones H, Olsson O, et al. Towards Molecular Genetic Improvement of Wood and Latex Production of Hevea brasiliensis: Enhancement of the Carbon Sink Capacity. The Proceedings on Fifth Joint Workshop of the Secretariat of the United Nations Conference on Trade and Development and the International Rubber Study Group on Rubber and the Environment. UK; International Rubber Study Group, Glasgow: 2002. p. 1-9.

5. Tissari J. Further development of the rubber wood processing industries in producer countries. Proceedings on Fifth Joint Workshop of the Secretariat of the United Nations Conference on Trade and Development and the International Rubber Study Group on Rubber and the Environment. Glasgow, UK; 2002. p. 34-78.

6. Peel JD. The suitability of rubber wood as a raw material for fibre board. The Malayan Forester. Malaysia; 1958;21:112-115.

7. Ratnasingam J, Scholz F. Yield studies of rubber wood lumber during rough milling operations. Holz als Roh- und Werkstoff. 2008;66(6):467-468.

8. Latif MA, Islam SMZ. Growth rate of Sissoo, Koroi, Akashmoni, Babla, Mahogany snd Raintree Planted on Embankment and Roadsides in the Coastal Areas of Bangladesh. Bangladesh J For Sci. 2001;30(1):52-57.

9. Nogueira EM, Fearnside PM, Nelson BW, et al. Estimates of forest biomass in the Brazilian Amazon: new allometric equations and adjustments to biomass from wood-volume inventories. Forest Ecology and Management. 2008;256:1853-1867.

10. Ketterings Q, Coe R, Noordwijk MV, et al. Reducing uncertainty in the use of allometric biomass equations for predicting above ground tree biomass in mixed secondary forest. Forest Ecology and Management. 2001;146:199-209.

11. Khan MNI, Suwa R, Hagihara A. Allometric relationships for estimating the aboveground phytomass and leaf area of mangrove Kandelia candal (L.) Druce trees in the Manko Wetland, Okinawa Island, Japan. Trees. 2005;19(3):266-272. 
12. Clough BF, Dixon P, Dalhaus O. Allometric relationships for estimating biomass in multistemed mangrove trees. Australian Journal of Botany. 1997;45(6):1023-1031.

13. Ong JE, Gong WK, Wong CH. Allometry and partitioning of the mangrove, Rhizophora apiculata. Forest Ecology and Management. 2004; 188:395-408.

14. Kusmana C, Sabiham S, Abe K, et al. An estimation of above ground tree biomass of the mangrove forest in East Sumatra, Indonesia. Tropics. 1992;1(4):243-257.

15. Poungparn S, Komiyama A, Patanaponpaipoon P, et al. Site independen allometric relationships for estimating above-ground weights of mangroves. Tropics. 2002;12(2):147-158.

16. Attiwill PM. Estimating branch dry weight and leaf area from measurement of branch girth in Eucalyptus. Forest Science. 1962;8:132-141.
17. Shinozaki K, Yoda K, Hozumi K, et al. A quantitative analysis of plant form-the species model theory. II. Further evidence of the theory and its application in forest ecology. Japanese Journal of Ecology. 1964;14(4):133-139.

18. Chave J, Andalo C, Brown S, et al. Tree allometry and improved estimation of carbon stocks and balance in tropical forests. Oecologia. 2005;145:87-99.

19. Avery TE, Burkhart HE. Forest Measurements. New York, USA: McGraw Hill; 1994. p. 408.

20. Burrows WH, Hoffmann MB, Compton JF, et al. Allometric relationships and community biomass estimates for some dominant eucalypts in Central Queensland woodlands. Australian Journal of Botany. 2000;48:707-714. 